BMJ Global Health

\section{The promise and pitfalls of social science research in an emergency: lessons from studying the Zika epidemic in Brazil, 2015-2016}

To cite: Passos MJ, Matta G, Lyra TM, et al. The promise and pitfalls of social science research in an emergency: lessons from studying the Zika epidemic in Brazil, 2015-2016. BMJ Global Health 2020;5:e002307. doi:10.1136/ bmjgh-2020-002307

Handling editor Seye Abimbola

Received 9 January 2020

Revised 25 March 2020

Accepted 25 March 2020

Check for updates

C Author(s) (or their employer(s)) 2020. Re-use permitted under CC BY-NC. No commercial re-use. See rights and permissions. Published by BMJ.

${ }^{1}$ Abraço a microcefalia, Salvador, Brazil

${ }^{2}$ Escola Nacional de Saúde Pública, Fundação Oswaldo Cruz, Rio de Janeiro, Brazil ${ }^{3}$ Aggeu Magalhães Institute, FIOCRUZ/PE, Recife, Brazil

${ }^{4}$ Faculty of Medicine, University of Pernambuco, Recife, Brazil

${ }^{5}$ Fernando Figueira Maternal and Children's Institute, FIOCRUZ, Rio de Janeiro, Brazil

${ }^{6}$ International Centre for Evidence in Disability, London School of Hygiene and Tropical Medicine, London, UK ${ }^{7}$ Infectious Disease Epidemiology, London School of Hygiene and Tropical Medicine, London, UK

Correspondence to Professor Hannah Kuper; Hannah.Kuper@Ishtm.ac.uk

\section{ABSTRACT}

Social science generates evidence necessary to control epidemics. It can help to craft appropriate public health responses, develop solutions to the epidemic impacts and improve understanding of why the epidemic occurred. Yet, there are practical constraints in undertaking this international research in a way that produces quality, ethical and appropriate data, and that values all voices and experiences, especially those of local researchers and research participants. In this paper, we reflected on the experience of undertaking social science research during the 2015/2016 Zika epidemic in Brazil. This experience was considered from the perspective of this paper's authors: three Brazilian academics, two UK academics and two mothers of children affected by congenital Zika syndrome. This group came together through the conduct of the Social and Economic Impact of Zika study, a mixedmethods social science study. The key findings highlight practical issues in the achievement of three goals: the conduct of high-quality social science in emergencies and efforts towards the decolonisation of global health in terms of levelling the power between Brazilian and UK researchers and optimising the role of patients within research. From our perspective, the information collected through social science was valuable, providing detailed insight into the programmatic needs of mothers and their affected children (eg, economic and social support and mental health services). Social science was considered a low priority within the Zika epidemic despite its potential importance. There were logistical challenges in conducting social science research, foremost of which are the difficulties in developing a trusting and balanced power relationship between the UK and Brazilian researchers in a short time frame. When these issues were overcome, each partner brought unique qualities, making the research stronger. The mothers of affected children expressed dissatisfaction with research, as they were involved in many studies which were not coordinated, and from which they did not see a benefit. In conclusion, the importance of social science in epidemics must continue to be promoted by funders. Funders can also set in place mechanisms to help equalise the power dynamics between foreign and local researchers, researchers and participants, both to promote justice and to create best quality data.
Summary box

Social science has the potential to generate evidence needed to control epidemics and cope with their aftermath, but it is rarely a key focus in these settings and receives more limited funding than epidemiology and basic science.

- Social science undertaken within the 2015/2016 Brazilian Zika epidemic highlighted the long-term impacts on the mothers of affected children and suggested how these could be overcome.

- However, the conduct of the research was challenging, not least because of logistical difficulties and concerns of power dynamics between the local and international researchers, and researchers and participants.

- Funders can play an important role in promoting social science in epidemics and in equalising the power dynamics between foreign and local researchers, researchers and participants.

\section{INTRODUCTION}

Epidemics are more than the spread of infectious agents through populations by vectors. They are phenomena experienced by individuals, families and communities, who are culturally and historically situated. ${ }^{1}$ These are people who fear the disease, suffer through illness, mourn fatalities and cope with the aftermath. People also play a critical role in epidemic control, as they are expected to change the way in which they eat, have sex, travel and go about their lives in order to stop the spread of infections. These interventions go to the heart of our everyday and most private behaviours, with the expectation that these will fundamentally change. This public health advice is unlikely to be followed unless there is trust in both the message and the messenger. $^{2}$ As one group working in the 2014-2015 Ebola described, 
People are expected to give up their loved ones to be taken away, often by foreigners with whom they have no relationship, to treatment centres where they will likely die with strangers. This helps explain why people often do not cooperate, even in the face of demands by those deemed to speak for them or threats of violent enforcement. ${ }^{4}$

Scientists and health professionals are also affected as they are mobilised to research and respond rapidly, even in a scenario of uncertainties.

Epidemic control therefore requires deep understanding of the needs, experiences, beliefs and intentions of people in order to craft appropriate public health responses. ${ }^{5}$ This information is collected primarily by social scientists. ${ }^{5-7}$ Social science can also help to identify the broad impacts of an epidemic and how these are culturally situated. This approach can be used to develop tailored solutions, as well as ensure that the interventions are acceptable and attentive to local conditions. Moreover, social science can shed light on why events unfolded in a certain way, what behavioural triggers were in place that allowed the epidemic to occur or persist in specific settings, ${ }^{3}$ as well as the broader political-economic forces that enabled the epidemic to emerge in the first place. Social science can provide critical insights into how communities cope in epidemics, drawing on local resources and knowledge, as well as uncovering the voices of those suffering. Diseases and epidemics do not exist in a vacuum, and social science can help to link nature and society, the individual and collective, biology and culture. ${ }^{8}$ However, this social science has to be done well.

The importance of social science is therefore, rightly, increasingly being recognised and supported. For instance, a WHO meeting was convened in 2017 on 'Integrating Social Science Interventions in Epidemic, Pandemic and Health Emergency response', and calls for social science research have accompanied those for epidemiology and basic science in the 2019-2020 coronavirus outbreak. Platforms have also been developed to support researchers in the conduct of social science in emergencies. ${ }^{910}$ However, important questions remain as to how this research should be conducted in a way that is ethical, practical, appropriate and of high quality. These questions relate strongly to debates around the decolonisation of global health, which is the attempt to address the entrenched power asymmetries in global health partnerships in the conduct of research, ${ }^{11}$ since social science in global health epidemics is rarely conducted exclusively by local researchers and usually involves international researchers.

These collaborations therefore bring into question issues around power and respect, ${ }^{12-15}$ as too often the high-income researchers control the research funding ${ }^{16}$ and take priority in publication authorship, ${ }^{1417}$ while the local researchers undertake the bulk of the data collection. There is often a focus in the literature on imbalances of authorship in collaborations between foreign high-income researchers and researchers in low-income and middle-income countries (LMICs), yet Abimbola argues that these imbalances are 'a tangible proxy for concerns about power asymmetries in the production (and benefits) of knowledge in global health'. ${ }^{11}$ We must therefore have more 'self-reflection' about 'foreign' and 'local' researchers' role in the research project, as well as the research publication process.

There is also another key group to consider in debates about decolonising global health: the people affected by the epidemics who are core to the research but often have a seemingly secondary status. They are often implicitly regarded as passive research participants whose only role is to give information. This perspective ignores their potential to help shape the research, interpret results and disseminate findings, and so improve the quality of the research. ${ }^{13} 18$ Furthermore, involvement in research could potentially decline unless participants are treated appropriately and see the value to their involvement, especially in these times of increasingly empowered patient populations.

The aim of this paper is to consider the experience of undertaking social science research within the context of the 2015/2016 Zika epidemic in Brazil and to suggest lessons learnt for future epidemics. Within this paper, we will reflect on the practicalities of conducting social science research within an epidemic and the value of the information collected. We will consider the perspectives of researchers from the UK and Brazil, and research participants, in this case mothers of children affected by congenital Zika syndrome (CZS).

\section{REFLECTING ON EXPERIENCE OF SOCIAL SCIENCE RESEARCH}

This paper reflects on the experience of social science research studies carried out in Brazil, funded by a nonBrazilian agency, where the research was undertaken jointly by Brazilian and UK researchers. The specific focus is the Social and Economic Impact of Zika Study. ${ }^{19}$ Our aim in that study was to describe the social and economic impacts of CZS in Brazil, considering families of children with CZS, health professionals, pregnant women and people of childbearing age. Our overall ambition therefore was to use social science approaches to identify the impacts and unmet needs as a result of the epidemic, and consequently to plan and advocate for better services to fill these gaps. There was a lack of other research groups addressing this topic.

This was a mixed-methods study, including the collection of qualitative, quantitative and economic data in order to explore the social and economic impacts of CZS in Brazil. Data were collected May 2017-January 2018 across two settings: Recife City and Jaboatão dos Guararapes in Pernambuco State (the epicentre of the epidemic), and the city of Rio de Janeiro (where reports of Zika virus infection and CZS were less frequent). In-depth qualitative interviews were conducted with mothers and other carers of children with CZS (approximately 30 per setting), pregnant women (10-12 per setting), men and women of childbearing age (16-20 per setting) and 
health professionals (10-12 per setting). Thematic analysis was undertaken independently by researchers from at least two research settings and shared for feedback. A case-control study was undertaken to explore quantitative social and economic differences between caregivers of a child with CZS (cases) and caregivers with an unaffected child (controls), including approximately 100 cases and 100 controls per setting. The primary caregiver, usually the mother, was interviewed using a structured questionnaire to collect information on a variety of measures (eg, mental health and quality of life) and economic impacts.

The study was conducted by researchers from Recife (Fiocruz and University of Pernambuco), Rio de Janeiro (Fiocruz) and the London School of Hygiene \& Tropical Medicine. The following procedures were put in place to strengthen the relationship of the team. Three joint meetings were held between the Brazilian and UK researchers in February 2017 (to agree on methods and approaches), July 2017 (to review data collection and agree publication plans) and February 2018 (to agree on an analytical framework). Additionally, there were regular Skype calls between the partners. Efforts were also made to improve the interaction with the mothers of children affected by CZS, who were the key research participants. The fieldwork was preceded by a workshop that involved the associations of mothers, feminists, researchers and others, to define and improve the research questions and instruments. The mothers were also included in the dissemination seminar, where they were invited to participate and respond to the data presented.

Our ambition was to undertake high-quality social science research while working in true partnership between the UK and Brazilian researchers and with the research participants. This paper considers the reflections of seven people involved in undertaking social science during the aftermath of the Zika epidemic in Brazil on whether these ambitions were realised. The authorship includes three Brazilian researchers (GM, TL and MEM), two British researchers (HK and LPK) and two mothers of children with CZS (JP and MM). HK, TL and MEM were joint principal investigators (PIs) of the 'Social and Economic Impacts of Zika' study, funded mostly by Wellcome and UKAID with a contribution from the European Union (EU)-funded Horizon 2020 programme. LPK is a qualitative researcher from the UK with 20 years of experience working in South Africa. GM is a Brazilian Social Scientist and established the Zika Social Sciences Network (https://fiocruz.tghn.org/zika-social-sciencesnetwork/), and therefore had a broad overview of social science conducted within the epidemic. JP and MM are mothers of children born with CZS and have established a large and influential parent group in Salvador (Abraco a Microcefalia, https://abracoamicrocefalia.apoiar.co/) to support and advocate for affected parents and children. They have both been research participants in multiple studies related to CZS.

These reflections on experiences and lessons learnt have emerged through a number of open and in-depth discussions between the authors. The first text of the paper was drafted (in English) by Hannah Kuper and then shared for the authors to make edits and additions until there was consensus as to its veracity and accurate reflection of the concerns of the group, and this process was repeated during the paper revision. All authors were proficient in English and were able to read and comment on the text. We have considered the entirety of the research cycle, from application through data collection to analysis and dissemination.

\section{THE START: APPLICATION FOR FUNDING FOR SOCIAL SCIENCE RESEARCH IN THE ZIKA EPIDEMIC Availability of funding}

Social science appeared to us to be a low priority in the Zika epidemic, and less important than other research areas - perceived as nice-to-have rather than fundamentally important. For instance, during a key stakeholder meeting on Zika at the WHO there were few, if any, social scientists present even though the focus was on how to support affected children. In consortia meetings, it appeared that more prestige and time were given to the laboratory and epidemiological sciences than social science studies. Furthermore, few funding streams were available to fund social science research (Wellcome and UKAID, Newton funds, Brazilian funding and components of EU Horizon 2020 grants). The Zika Social Science Network estimates that in the period 2015-2018, only \$3.8 million in research funding was available for Zika and Social Science research (more than half from Wellcome/UKAID). By comparison, far larger contributions were made to research on Zika in general, including from the EU (\$51 million in 2016) and the National Institutes of Health (\$81 million allocated in 2016), among others.

\section{Application for funding}

The available funding streams were mostly for the conduct of research in emergencies, and therefore the application procedures were rapid, which created challenges. The financial and administrative structures in many universities made it difficult to meet such tight deadlines, including applications for ethical approval, although fast-track procedures were put in place in Brazil. Rapid proposal writing was also complicated. For our grant (Social and Economic Impact of Zika study), the proposal writing was led by the UK researchers with input from Brazilian partners. This process is common because of the often greater experience of UK researchers in international grant writing and the fact that some funding bodies (eg, Newton) required a UK research lead. However, this distribution of roles has the potential to create inequities between the Northern and Southern partners. The application process is the time when roles, responsibilities and funding are divided between different partners, in other words, the time when power is allocated. These decisions require sensitivity, trust, and understanding of mutual strengths and weaknesses. 
It was difficult to establish the necessary relationships between UK and Brazilian researchers in the short period of time when the application was written, and so our study was started without some of these fundamental questions ironed out, which created sensitivities. In particular, there was concern from the Brazilian partners that the UK researchers did not respect their skill set or experience sufficiently, and that the UK researchers were unfamiliar with the Brazilian setting. These issues were amplified by the language barriers between the groups, as several of the Brazilian researchers could not communicate well in English and the UK researchers knew no Portuguese. Moreover, in our study, the two Brazilian partners did not know each other well and came from different regions of Brazil, which had their own power imbalances. All these factors created initial weariness that needed to be overcome, and one important positive factor in our application is that the PI role was shared jointly between investigators from the two Brazilian and UK site (MEM, TL and HK).

Issues of funding and leadership were perhaps more complex in Brazil than in other settings. There is a strong and well-established public health research infrastructure in Brazil, which is over a century old. Brazilian academics are therefore well placed to have led much of the research needed on Zika, as they had the relevant skills, experience and connections. Additionally, they had a deep familiarity with language and cultural, social and political contexts. ${ }^{20}$ However, most funding for studies in Brazil during the Zika epidemic was awarded to European and USA researchers, ${ }^{21}$ as is common with global health research funding. ${ }^{16}$ This situation, understandably, created some resentment on the side of Brazilian researchers towards international academics.

At the same time, many Brazilian researchers were overloaded as they were part of many different new applications and studies, in addition to their ongoing commitments, including high teaching loads, and so benefitted from the support of the international researchers. There were also areas of specific expertise where input from international partners was helpful - in our study this was in terms of economic modelling, experience working in the disability field and writing for international journals, as well as providing input into the tool design and data analysis. It was therefore beneficial for both Brazilian and international researchers to come together in applying for funds, but negotiating the balance and roles took sensitivity and time and, in an emergency, time is in short supply.

\section{THE MIDDLE: CONDUCT OF SOCIAL SCIENCE RESEARCH IN THE ZIKA EPIDEMIC \\ Data collection}

Project coordination was generally shared between the UK and Brazilian PIs. The majority of the data collection-whether qualitative or quantitative-was conducted by Brazilian researchers, while the UK academics were more engaged in developing the data collection tools and approaches, in collaboration with the Brazilian team.
This distribution of work was considered acceptable by the researchers in our study, but this task allocation may be regarded as unequal by others, or in other settings.

There were a number of complexities that arose during data collection. The mothers of affected children, who were usually the main caregivers, were often engaged in multiple studies, on top of their extensive responsibilities in looking after their child and other existing commitments, and so were overloaded.

The mothers had a mixed understanding of the benefit from their engagement in the research, either personally or in terms of improved care for affected children in general. One mother remarked:

For me, it was very important to be part of the research, since I was in the middle of a new problem that needs to be investigated in order to enable new care and prevention treatments.

\section{But another mother noted:}

Frankly speaking, I think that most families did not see any personal gains from the research. I think those families that have a better understanding, can understand that these studies can improve the quality of life in the future. But the vast majority, with low education, are so involved with their day-to-day issues that stopping to devote some time to research seems like a waste of time. And that is a great challenge: to reconcile the importance of research with the day of families and their real needs. I think that research and researchers need to include in the scope a real and direct counterpart, that benefits the family now and not in the future - which can be very distant.

This issue was compounded by the fact that the mothers reported being resentful that they were asked the same questions repeatedly in uncoordinated way by different researchers. There was also sensitivity about the type of questions being asked-such as the repeated focus on poverty and living situations-especially since the Brazilian researchers were mainly white middle-class academics, while most of the mothers were poor and from ethnic minorities. At times, the mothers even felt exploited by researchers; for instance, there were reports of researchers infiltrating the parent groups or WhatsApp networks that parents had established to provide peer support in order to collect information for their studies. It was therefore an important ethical concern for us that we were collecting data on social and economic impacts, even if no solution was available or being offered. As a consequence, we sought additional funding to develop services and interventions, as described below. ${ }^{22}$

Other data collection issues were specific to the time and the setting. The Zika epidemic occurred around April-May 2015, and the majority of affected babies were born late 2015 to early $2016 .^{23}$ Therefore, the epidemic had passed by the time that research funding became available during late 2015 and early 2016. The end of the epidemic was of course welcomed, but it also created difficulties for many researchers, for instance, those trying to develop diagnostic tests or vaccines or track 
the incidence of CZS among infected pregnancies. The conduct of social science was also more difficult, such as the investigation of whether the Zika epidemic affected reproductive decision making.

\section{Collaboration between Brazilian and UK researchers}

The establishment of trust was a critical element to the success of our study. We built trust between the Brazilian and UK researchers through having transparent arrangements for funding and ensuring that the groups had separate and equal amounts of funding, and each had a PI. The three workshops (two held in Recife and one in in Rio de Janeiro) allowed for open discussion about roles and responsibilities, including authorship on papers, and a strengthening of relationships between the researchers. In these meetings, we explicitly discussed power imbalances and roles, and our desire to do this project in a way that recognised what each of us brought to the project and how we would avoid neocolonial dynamics that can develop in such internationally funded projects.

Another important component was that all three groups were high-quality research institutions; the UK team members had extensive experience of working internationally, and the Brazilian researchers were highly practised in working with international partners and had the confidence to voice concerns about how the project was run. We also worked to build trust between the mothers of affected children and the researchers, in particular the Brazilian researchers. One facilitator to building trust with the mothers is that the Brazilian researchers were from a reputed institution, connected with service delivery to the children. Furthermore, the Brazilian researchers made concerted efforts to connect with the key mother's organisations, and the mothers were invited to contribute towards the research planning and to speak at dissemination and other events, showing respect to these organisations. We considered that a high refusal rate by the mothers of affected children was likely without these trusting relationships.

\section{THE AFTERMATH: DATA ANALYSIS, DISSEMINATION AND RESEARCH UPTAKE \\ Data analysis}

The analysis of qualitative data arguably takes longer than quantitative data analysis, and in our study this was particularly challenging given the large number of transcripts generated. Consequently, rapid outputs were difficult to achieve. Another issue was that interviews were undertaken in Portuguese, creating barriers to the UK researchers' ability to analyse data, yet translations added further costs and time. We therefore decided to not translate all interviews, which was possible as we had included a Brazilian researcher in the UK team. Another problem in the qualitative analysis was having common theoretical frameworks. There are a number of Brazilian medical and sociological journals that many of the Brazilian academics read regularly and published in. Yet, many of these articles were in Portuguese and were not accessible to UK researchers, while several of the Brazilian researchers struggled to read the Englishlanguage articles. There were also divergent opinions on focus. For instance, the Brazilian researchers often saw the political upheavals that were happening in Brazil at the time of the Zika outbreak as vital to understanding the context, while the UK colleagues often wanted only a short summary of the context for the introduction.

There was a view expressed a number of time that foreigners were interested because Zika might be a risk to the global community, but were less concerned with the health concerns of Brazilians, of which Zika was only one of many. On the other hand, the UK researchers made comparisons of the Zika epidemic with the West Africa Ebola outbreak of 2014/2015, whereas for many of the local Brazilian researchers and people interviewed, Ebola was a different disease, happening in a different context and was not relevant to thinking about Zika. Despite these hurdles, there was an important role for the UK researchers in data analysis and interpretation, alongside the Brazilian team, such as specific contributions towards the conceptualisation of disability, and economic modelling. The UK researchers helped to shift the focus beyond Brazil, so that articles were written for an international audience and acknowledged the international literature. The UK researchers learnt much from the Brazilian colleagues, not only about Zika and Brazil but also about the Brazilian concept of 'collective health', which expresses health and disease as resulting from political, social, cultural and biomedical influences.

\section{Key findings from the social science study}

In our opinion, social science provided crucial information that would not otherwise have been documented. For instance, our Social and Economic Impacts of Zika study showed the severe strain that caregivers were experiencing in looking after their child, often resulting in depression and financial hardship. ${ }^{24}$ At the same time, these experiences were just one of a number of difficulties in their lives, such as concerns about local gangs and security, as Zika disproportionately affects poor and vulnerable families. We also observed that problems of caregivers were compounded by difficulties seeking care and lack of coordination of services, as well as gaps in the knowledge of healthcare providers. ${ }^{25}$ We demonstrated that there are high costs incurred, both on the side of the affected families and the healthcare system, which had potentially large financial impacts (paper in submission). This information is critical to improving services to better support the affected children and their families, and prior to our study was assumed but not documented systematically. We used a range of ways for data collection to collect rich information, addressing some of the concerns of critics like Abimbola that 'the sense of complexity and of multidimensional reality that is often necessary to address delivery problems in global health is frequently lost in international publications. ${ }^{11}$ 


\section{Data dissemination}

We used multiple approaches to disseminate the data and findings from our study, in order to advocate for more and better services to support the affected children and families. Wellcome and other agencies are rightly committed to making data openly available. ${ }^{26}$ However, this was difficult. The number of children with Zika was relatively small-around 3000 across Brazil-and so there are real concerns that the individual women could be identified in both the quantitative and qualitative data. Identification would be highly inappropriate as women shared sensitive information regarding poverty status, mental health and potentially abortion. We therefore made the methods for data collection available and have clarified that applications can be made for the data, which will be considered by a committee. Publications have been submitted to and published in peer-reviewed international journals. ${ }^{192425} 27$ Dissemination events were held in Brazil and in the UK. In Recife, a 1-day workshop was held, including researchers, healthcare professionals, Ministry of Health personnel and mothers of affected children. In the UK, dissemination events occurred at London School of Hygiene and Tropical Medicine, conferences and Wellcome. These included presentations by UK researchers of the project and reflections by two mothers of affected children (JP and MM). Joana and Mila were interviewed by a number of media outlets during their visit to the UK (eg, Channel 4 and ITV news, the Telegraph, BBC World Service). The research findings were also disseminated through blogs, conference and seminar presentations, and video interviews.

\section{Moving findings into practice}

Our group used these findings to attempt to improve services and fill gaps for carers of children with CZS. Wellcome and UKAID funded our group to develop parent support groups for carers of children with CZS, using the data gathered through our study to tailor the programme. ${ }^{22}$ This 10 -week programme runs in the local community and covers sessions such as feeding, communication and play, as well as a psychosocial support component was introduced to address the mental health concerns among the parents. Almost 100 families in Brazil and Colombia have now taken part in this programme. Additionally, Newton Grant funded the development of an online course on Integrated Healthcare for Children with Developmental Disabilities to address the information gaps of healthcare workers identified by our research. This course has been developed in English and in Portuguese to reach national and international audiences. New grants have also been funded to explore the issues raised by the research in more detail, such as the general exclusion of people with disabilities from the health system in Brazil. Finally, the mothers of children with CZS raised issues around the inclusion of their children in schools, and so a grant application has been made to address this issue. The relationship has been more secure between the Brazilian and UK researchers when collaborating on these grant applications, and so some of the issues that existed in the current study were avoided.

The research provided information for mothers to continue to advocate for better services. As an example, the Zika Social Science Network organised a large meeting, including scientists, health authorities and social movements (mothers associations) in 2018, in Rio de Janeiro. This meeting provided a forum to discuss and exchange different experiences, narratives and perceptions about the Zika outbreak and its repercussions, and to build recommendations to respond to the Zika aftermath. A document was created from the meeting, which has been used by researchers and social movements in different political arenas to advocate for the affected children and their families. An unexpected additional benefit of the study was that the social scientists became allies of and advocates for the carers of affected children. For instance, in international and national expert meetings, they frequently raised the concerns of parents and the need for sensitivity towards this group. We were also, perhaps, among the few that invited mothers of affected children to speak at events, and disseminated information directly back to this group.

Yet, postepidemic research, funding and social support for affected people continue to be missed by global health initiatives, ${ }^{28}$ and the affected families continue to live with unmet needs, such as for mental healthcare services for mothers or educational inclusion for the child. There is therefore still frustration on the side of mothers that research has not always translated into action. One mother said, 'We know it is not an easy task, but researchers must find ways of linking their research to the quality of care provided to children and their families.' There was understanding that many benefits from research would be in the future, in the next epidemics, but in the meantime, the mothers expressed a desire for more feedback from the research, including the results of lab exams or anthropometric data, and potentially offering access to treatments, orthoses or further assistance. It was also recognised that more funds appear to be available for research than for implementation of programmes with respect to Zika. This is likely to be a particular concern within the current economic and political crisis in Brazil, which has resulted in austerity policies and cuts in federal funding to public health, science and technology, and education. ${ }^{29}$

\section{LEARNINGS AND RECOMMENDATIONS}

This paper describes the experience of undertaking social science research within the context of the 2015/2016 Zika epidemic in Brazil, from the perspective of UK and Brazilian researchers, as well as mothers of affected children. The findings of this paper highlight practical issues in the achievement of three goals: the conduct of highquality social science in emergencies, efforts towards the decolonisation of global health in terms of levelling the power between Brazilian and UK researchers, and optimising the role of patients within research. These matters will be considered, in turn. 
From our perspective, the information collected in the Social and Economic Impact of Zika study was valuable, providing detailed insight into the programmatic needs of mothers and their affected children, such as for economic and social support, mental health services and better coordination of health services. ${ }^{19} 242527$ Of course, we were not the only social scientists working within the Zika epidemic. Notably, Debora Diniz and team conducted excellent research probing the rights and realities of women affected by Zika in Brazil, ${ }^{30-34}$ but there are too few other examples. Despite its potential importance, social science appeared to be a low priority within the Zika epidemic. The vast majority of research funding was given to investigate the epidemiology of the disease, develop a diagnostic test, vaccine and control strategy, and to understand the biological mechanisms. ${ }^{21}$ The lack of social science meant that mistakes were made during the control of Zika. For instance, during the 2015/2016 Zika epidemic, public health messages focused on avoiding pregnancy, although women frequently had poor control of their fertility; using insect repellents or staying in air-conditioning, which was not possible for poorer families and covering up to avoid mosquito bites, despite the high temperatures in Brazil. ${ }^{21}$ This situation may have changed since 2016, with more value now being placed on the importance of social science in epidemic controls. ${ }^{9} 10$

There are ongoing debates on decolonisation of global health, and the role of high-income country researchers in studies conducted in LMICs. ${ }^{12-15}$ These debates argue that global health has its roots in colonial or tropical medicine and that there is an inherent unequal power dynamic between the partners from richer and poorer settings, in terms of funding, roles and responsibilities and research outputs. ${ }^{13}{ }^{15}$ This dynamic can result in both 'parachute' and 'parasitic' research in international collaborations, where Northern researchers drop into Southern settings to undertake research without equitable treatment of Southern partners. ${ }^{35}$ Our experience from the current study shows that there are potentially real logistical issues in international collaborative research, but that each partner can bring unique qualities, making the research efforts stronger. It was clear that the role of the Brazilian academics was critical, as it was 'their' epidemic in 'their' setting. However, the UK researchers also made important contributions in terms of application for funding, bringing in specific technical expertise, particularly with respect to conceptualisation of disability and economic modelling, and facilitating the development of papers for an international audience.

Another key benefit was that the UK researchers helped to situate the research into an international arena, adding a foreign gaze to the local knowledge and helping to look beyond the Brazilian context to understand the international implications. A fundamental problem was that the way that the grants were set up-with a focus on a UK researcher in a lead role-created an uneven power dynamic that could only be overcome through building a close and trusting work relationship between
UK and Brazilian partners. Arguably, decolonisation was not achieved as the majority of our data collection was conducted by Brazilian academics, with the UK researchers devoting more attention to writing the grant and finalising papers, but there was a feeling of equality between the partners. This situation was, perhaps, not typical of all global health collaborations, given that the Brazilian academics were from elite, internationally recognised organisations, but may be reflective of future scenarios as research capacity develops in many LMICs.

These issues surrounding decolonisation of global health go beyond consideration of the relationship of the national and international researcher, but also affect the research participants, and the recognition of the importance of individual and community assets in the research process. ${ }^{13} 18$ There was widespread dissatisfaction with research from the perspective of the mothers of children affected by Zika, as they were involved in many studies which were not coordinated, and from which they did not see a benefit. However, the mothers on their own were unlikely to have the skills to undertake the research, nor the time or knowledge of theoretical constructs, and so the researchers did play an important role in compiling their narratives and experiences. We made attempts to work more collaboratively with the mothers, and believe that we achieved some successes and that the study and dissemination activities were stronger as a consequence. Even stronger collaboration with the mothers would have further improved the dissemination activities and the potential for research uptake, and should be a focus in future research projects. This input should be throughout the research cycle-identifying research question, designing, undertaking, analysing and disseminating research-though currently this type of patient engagement seems to happen rarely, and inconsistently, in LMIC research. ${ }^{18} \mathrm{~A}$ continued focus on moving evidence into practice is needed and will likely help gain support from the patient population.

There are important strengths to this research. The perspectives of three different groups were reflected: UK and Brazilian researchers and Brazilian mothers of children with disabilities. The individuals writing the paper had established relationships of trust and held a series of open discussions about these issues. There was also a process of reviewing, debating and agreeing on the paper, so that the text was agreed by all authors. In terms of limitations, the authors were not representative of all researchers or mothers; the Brazilian researchers came from elite organisations and the mothers were middleclass, well educated and leaders of a large parent support group. The paper also reflects on only one setting: the Zika epidemic of 2015/2016. Data collection for this paper was not undertaken in a structured way, and so may be subject to bias.

Key learnings and recommendations have emerged from our reflections on the role of social science in the Zika epidemic. We believe that the debate has moved from whether this research should be conducted to how 
and in a way that is ethical, practical, appropriate and of high quality. Consideration should be given to allocating more funds to social science in future epidemics, and there is evidence that this is occurring, for instance, with respect to the 2019-2020 coronavirus epidemic. This funding should be directed more routinely to the local researchers in order to raise their autonomy. They may then choose or be facilitated to invite international experts with complementary skills. A two-stage application procedure may be helpful (eg, as used by $3 i e$ ). In the first stage, there is an initial application fund, and then funds are given for a planning workshop where a full proposal can be developed for the second-stage application. This process can give time for research collaborators to meet, discuss issues and build trusting relationships.

It is critical that funding agencies promote the coordination of data collection between researchers from different groups, to prevent duplication of efforts and overloading patients unnecessarily. One template to achieve this ambition is through establishing platforms, such as the Ebola Response Anthropology Platform (http://www.ebola-anthropology.net/) or the Zika Social Science Network, as well as platforms that provide guidance on the conduct of research. ${ }^{9}{ }^{10}$ A stronger emphasis must be given to true engagement with affected groups, as well as disseminating information in a way that allows positive action to be taken. Funding agencies can strengthen emphasis on the inclusion of patient groups in steering committees, and make feedback to these groups mandatory, perhaps requiring funds to be allocated to these activities. Furthermore, research funders can make stronger links with implementing agencies to increase the likelihood of the uptake of recommended practices, as we cannot argue that the findings are useful unless they improve practice.

\section{CONCLUSION}

In conclusion, there is increasing recognition of the importance of social science in epidemics. These research efforts must respect both local and international researchers, as well as the people researched, in order to produce high-quality, practicable and impactful evidence. Funders can play an important role in promoting social science in epidemics and in equalising the power dynamics between foreign and local researchers, researchers and participants.

Contributors All authors contributed critically and equally to the conceptualisation, drafting and editing of the paper.

Funding The Social and Economic Impact of Zika study was supported by the Wellcome Trust \& the UK's Department for International Development (205377/Z/16/Z to LCR, https://wellcome.ac.uk/); the European Union's Horizon 2020 research and innovation programme (https://ec.europa.eu/programmes/ horizon2020/) under ZikaPLAN grant agreement number 734584, https://zikaplan. tghn.org/).

Disclaimer The funders had no role in study design, data collection and analysis, decision to publish, or preparation of the manuscript.

Competing interests None declared.
Patient and public involvement Patients and/or the public were involved in the design, conduct, reporting or dissemination plans of this research. Refer to the Methods section for further details.

\section{Patient consent for publication Not required.}

Ethics approval Ethical approval for the full study was received from London School of Hygiene and Tropical Medicine and the Fiocruz ethics committee (CAAE 60682516.2.1001.5269).

Provenance and peer review Not commissioned; externally peer reviewed.

Data availability statement № additional data are available.

Open access This is an open access article distributed in accordance with the Creative Commons Attribution Non Commercial (CC BY-NC 4.0) license, which permits others to distribute, remix, adapt, build upon this work non-commercially, and license their derivative works on different terms, provided the original work is properly cited, appropriate credit is given, any changes made indicated, and the use is non-commercial. See: http://creativecommons.org/licenses/by-nc/4.0/.

Author note The authors were all critically important to the conduct of this research. The authorship order was randomised to achieve a lack of hierarchy.

\section{ORCID iD}

Hannah Kuper http://orcid.org/0000-0002-8952-0023

\section{REFERENCES}

1 Haraway D. Situated Knowledges: the science question in feminism and the privilege of partial perspective. Feminist Studies 1988; $14: 575$

2 Caleo G, Duncombe J, Jephcott F, et al. The factors affecting household transmission dynamics and community compliance with Ebola control measures: a mixed-methods study in a rural village in Sierra Leone. BMC Public Health 2018;18:248.

3 Coltart CEM, Lindsey B, Ghinai I, et al. The Ebola outbreak, 20132016: old lessons for new epidemics. Philos Trans $R$ Soc Lond B Biol Sci 2017;372:20160297.

4 Parker M, Hanson TM, Vandi A, et al. Ebola, community engagement, and saving loved ones. Lancet 2019;393:2585.

5 WHO. Community engagement and social mobilization. Geneva: WHO, 2019. https://www.who.int/csr/disease/ebola/training/ community-engagement/en/

6 Janes CR, Corbett KK, Jones JH, et al. Emerging infectious diseases: the role of social sciences. Lancet 2012;380:1884-6.

7 Stellmach D, Beshar I, Bedford J, et al. Anthropology in public health emergencies: what is anthropology good for? BMJ Glob Health 2018;3:e000534.

8 Hacking I. The social construction of what? Cambridge, MA and London: Harvard University press, 2000.

9 UNICEF and IDS. The social science in humanitarian action: a communication for development platform, 2020. Available: https:// www.glopid-r.org/our-work/social-science-research/ [Accessed 4 Mar 2020].

10 GloPID-R. Global research collaboration for infectious disease preparedness, 2020. Available: https://www.glopid-r.org/our-work/ social-science-research/ [Accessed 4 Mar 2020]

11 Abimbola S. The foreign gaze: authorship in academic global health BMJ Glob Health 2019;4:e002068.

12 Reidpath DD, Allotey P. The problem of 'trickle-down science' from the Global North to the Global South. BMJ Glob Health 2019;4:e001719.

13 Keikelame MJ, Swartz L. Decolonising research methodologies: lessons from a qualitative research project, Cape Town, South Africa. Glob Health Action 2019;12:1561175

14 Hedt-Gauthier BL, Jeufack HM, Neufeld NH, et al. Stuck in the middle: a systematic review of authorship in collaborative health research in Africa, 2014-2016. BMJ Glob Health 2019;4:e001853.

15 Saha S, Kavattur P, Goheer A. The C-WORD: tackling the enduring legacy of colonialism in global health. Health Systems Global, 2019

16 Abimbola S, Negin J, Martiniuk A. Charity begins at home in global health research funding. Lancet Glob Health 2017;5:e25-7.

17 Mbaye R, Gebeyehu R, Hossmann S, et al. Who is telling the story? A systematic review of authorship for infectious disease research conducted in Africa, 1980-2016. BMJ Glob Health 2019;4:e001855

18 Cook N, Siddiqi N, Twiddy M, et al. Patient and public involvement in health research in low and middle-income countries: a systematic review. BMJ Open 2019;9:e026514. 
19 Kuper H, Lyra TM, Moreira MEL, et al. Social and economic impacts of congenital Zika syndrome in Brazil: study protocol and rationale for a mixed-methods study. Wellcome Open Res 2018;3:127.

20 Gibb R, Danero Iglesias J. Breaking the silence (again): on language learning and levels of fluency in ethnographic research. Sociol Rev 2017;65:134-49.

21 Goodridge K, Reveiz L, Elias V. An overview of financial sources being utilized to support Zika virus published research. PLoS One 2017;12:e0183134.

22 Duttine A, Smythe T, Calheiro de Sá MR, et al. Development and assessment of the feasibility of a Zika family support programme: a study protocol. Wellcome Open Res 2019;4:80.

23 Musso D, Ko Al, Baud D. Zika virus infection - after the pandemic. N Engl J Med 2019;381:1444-57.

24 Kuper H, Lopes Moreira ME, Barreto de Araújo TV, et al. The association of depression, anxiety, and stress with caring for a child with congenital Zika syndrome in Brazil; results of a cross-sectional study. PLoS Negl Trop Dis 2019;13:e0007768.

25 Albuquerque MSV, Lyra TM, Melo APL, et al. Access to healthcare for children with congenital Zika syndrome in Brazil: perspectives of mothers and health professionals. Health Policy Plan 2019;34:499-507.

26 Wellcome Trust. Statement on data sharing in public health emergencies, 2016. Available: https://wellcome.ac.uk/what-we-do/ our-work/statement-data-sharing-public-health-emergencies
27 Moreira MCN, Nascimento M, Mendes CHF, et al. Emergency and permanence of the Zika virus epidemic: an agenda connecting research and policy. Cad Saude Publica 2018;34:e00075718.

28 Vargha D. After the end of disease; rethinking the epidemic narrative. Somatsopherenet 2016.

29 Matta GC, Nogeuiera C, Rabello ET. Zika outbreak in Brazil: in times of political and scientific uncertainties, mosquitoes can be stronger than a c ountry. In: Lynteris C, ed. Framing animals as epidemic villains: histories of non-human disease vectors. Manchester: Palgrave Macmillon, 2019: 211-28.

30 Diniz D, Medeiros M, Madeiro A. Brazilian women avoiding pregnancy during Zika epidemic. J Fam Plann Reprod Health Care 2017;43:80.

31 Diniz D, Brito L, Ambrogi I, et al. Understanding the sexual and reproductive health needs in Brazil's Zika-affected region: placing women at the center of the discussion. Int J Gynaecol Obstet 2019;147:268-70.

32 Diniz D. Zika virus and women. Cad Saude Publica 2016;32:e00046316.

33 Rasanathan JJK, MacCarthy S, Diniz D, et al. Engaging human rights in the response to the evolving Zika virus epidemic. Am J Public Health 2017;107:525-31.

34 Diniz D, Gumieri S, Bevilacqua BG, et al. Zika virus infection in Brazil and human rights obligations. Int J Gynaecol Obstet 2017;136:105-10.

35 The Lancet Global Health. Closing the door on parachutes and parasites. Lancet Glob Health 2018;6:e593. 